\begin{tabular}{|c|c|c|}
\hline \multirow{3}{*}{$\begin{array}{r}\text { Case Reports in } \\
\text { Gastroenterology }\end{array}$} & \multirow{2}{*}{\multicolumn{2}{|c|}{ Case Rep Gastroenterol 2014;8:371-376 }} \\
\hline & & \\
\hline & $\begin{array}{l}\text { DOI: } 10.1159 / 000369548 \\
\text { Publisned online: November 22, } 2014\end{array}$ & $\begin{array}{l}\text { (c) } 2014 \text { S. Karger AG, Basel } \\
\text { 1662-0631/14/0083-0371 } \$ 39.50 / 0 \\
\text { www.karger.com/crg }\end{array}$ \\
\hline & \multicolumn{2}{|c|}{$\begin{array}{l}\text { This is an Open Access article licensed under the terms of the Creative Commons } \\
\text { Attribution-NonCommercial } 3.0 \text { Unported license (CC BY-NC) (www.karger.com/OA } \\
\text { license), applicable to the online version of the article only. Distribution permitted for non } \\
\text { commercial purposes only. }\end{array}$} \\
\hline
\end{tabular}

\title{
Gastroduodenal Intussusception, Intermittent Biliary Obstruction and Biochemical Pancreatitis due to a Gastric Hyperplastic Polyp
}

\author{
Elie Chahla ${ }^{a}$ Michael A. Kim ${ }^{d} \quad$ Brandon T. Beal $^{d} \quad$ Samer Alkaade $^{a}$ \\ Robert W. Garrett ${ }^{b}$ Louay Omran ${ }^{a}$ Michael T. Ogawa ${ }^{c}$ Jason R. Taylor ${ }^{a}$ \\ ${ }^{a}$ Division of Gastroenterology and Hepatology, ${ }^{b}$ Department of Radiology and \\ ${ }^{c}$ Department of Internal Medicine, Saint Louis University School of Medicine, and \\ ${ }^{\mathrm{d}}$ Saint Louis University School of Medicine, St. Louis, Mo., USA
}

\section{Key Words}

Gastroduodenal intussusception · Intussusception $\cdot$ Hyperplastic polyp $\cdot$ Biliary $\cdot$ Pancreatitis

\begin{abstract}
We present the case of a 76-year-old man with gastroduodenal intussusception secondary to a gastric hyperplastic polyp. Intussusception in the adult population occurs infrequently. Our patient presented with gastroduodenal intussusception, which is very uncommon and accounts for $<10 \%$ of all types of intussusception. This case is unique in that partial endoscopic resection of the gastric hyperplastic polyp resolved the patient's gastroduodenal intussusception, biliary obstruction and biochemical pancreatitis without the need for surgical intervention.

(c) 2014 S. Karger AG, Basel
\end{abstract}

\section{Introduction}

Gastroduodenal intussusception is rare in adults and accounts for approximately $10 \%$ of all intussusceptions [1]. Gastroduodenal intussusception usually occurs when a pedunculated lesion acts as a lead point for anterograde prolapse of the gastric wall. Common etiologies include both benign and malignant lesions, including smooth muscle tumors, hyperplastic and adenomatous polyps, lipomas, and rarely a malignant mass [2-6].

Hyperplastic polyps are the second most common cause of gastric polyps, with a strong association to chronic mucosal proliferation in the context of Helicobacter pylori infection or 
Chahla et al.: Gastroduodenal Intussusception, Intermittent Biliary Obstruction and Biochemical Pancreatitis due to a Gastric Hyperplastic Polyp

autoimmune disease $[7,8]$. Patients with these polyps typically remain asymptomatic, but some may present with dyspepsia, abdominal pain or gastrointestinal bleeding [9]. Hyperplastic polyps rarely cause gastroduodenal intussusception. Gastroduodenal intussusception has a nonspecific presentation, but symptoms may consist of abdominal pain, dyspepsia, nausea and vomiting $[4,5]$. Concurrent laboratory abnormalities such as elevated lipase or amylase may also be noted on presentation $[1,4,5]$.

The management of gastroduodenal intussusception includes reducing the size of the mass acting as a lead point and subsequent resection [1]. Histopathology is necessary for all hyperplastic polyps to determine the presence of dysplasia or malignancy. Dysplastic transformation to malignancy is possible but rare, thus appropriate surveillance follow-up is necessary [8].

Currently, there are no formal guidelines in the literature for the management of gastroduodenal intussusception caused by nondysplastic hyperplastic polyps [8]. The main source of information on nondysplastic hyperplastic polyps is in case reports and case series. In the documented cases of gastroduodenal intussusception, large polyps were usually resected surgically $[4,10]$.

We herein report a case of a large, nondysplastic, hyperplastic gastric polyp causing gastroduodenal intussusception, biliary obstruction and biochemical pancreatitis, treated solely with endoscopic management. Informed consent was obtained for this case report.

\section{Case Report}

A 76-year-old man presented to the emergency department with a 1-day history of abdominal pain, nausea and nonbloody emesis. His abdominal pain was severe, constant and located in the mid-epigastric region, with radiation to his back. He denied a prior history of these symptoms. His past medical and surgical history were notable for a myocardial infarction requiring percutaneous coronary intervention 6 months prior, type II diabetes mellitus, hypertension, hyperlipidemia and cholecystectomy. In addition to his other outpatient medications, he was taking ticlopidine and aspirin. He had a 15 pack-year smoking history and prior alcohol use, but was abstinent from both.

On admission, his vital signs were stable. His physical exam was remarkable for epigastric abdominal tenderness with voluntary guarding. Laboratory studies were notable for a white blood cell count of $12,600 / \mu \mathrm{l}$, alanine aminotransferase of $74 \mathrm{U} / \mathrm{l}$, aspartate aminotransferase of $243 \mathrm{U} / \mathrm{l}$, alkaline phosphatase of $198 \mathrm{U} / \mathrm{l}$, total bilirubin of $1.1 \mathrm{mg} / \mathrm{dl}$ and serum lipase of 3,668 U/l. His creatinine was within normal limits.

Pancreatic protocol computed tomography (CT) of the abdomen showed gastric antral wall thickening and a dilated and fluid-filled duodenum with wall thickening, but no evidence of small bowel obstruction, peripancreatic edema or fat stranding. Esophagogastroduodenoscopy (EGD) revealed a fluid-filled and distended stomach due to partial gastric outlet obstruction from a large fungating, gastric polyp (fig. 1). The polyp was approximately $12 \mathrm{~cm}$ in width, $10 \mathrm{~cm}$ in length and multi-lobulated, with a $10 \mathrm{~cm}$ base. Endoscopic ultrasound showed that the polyp involved the superficial and deep mucosal layers of the gastric wall without further invasion. Stack biopsies of one section of the polyp confirmed the presence of a hyperplastic gastric polyp without dysplasia. $H$. pylori immunostain was also negative. Further resection could not be performed due to the patient's current ongoing intake of ticlopidine and aspirin. He was recommended to have endoscopic resection, but he requested to be discharged home. 
Chahla et al.: Gastroduodenal Intussusception, Intermittent Biliary Obstruction and Biochemical Pancreatitis due to a Gastric Hyperplastic Polyp

The following day, he returned to the emergency department with recurrent symptoms. CT of the abdomen with contrast was again performed and showed gastroduodenal intussusception with gastric outlet obstruction secondary to the gastric mass acting as a lead point (fig. 2, fig. 3). There was also biliary ductal dilation on imaging as well as persistently elevated liver tests. Lipase continued to be elevated, but again no radiographic evidence of pancreatitis was noted. We elected to endoscopically treat the polyp a few days later, which was a total of 5 days after stopping his dual antiplatelet therapy.

At the time of EGD, we used a through-the-scope, 15-mm, controlled radial expansion balloon. We passed the endoscope beyond the lead point of the polyp and inflated the controlled radial expansion balloon to $15 \mathrm{~mm}$. We then pulled the balloon and polyp back into the stomach. This successfully treated the gastroduodenal intussusception. Because of the high likelihood of recurrent intussusception, we attempted endoscopic resection of the gastric polyp. Due to the broad base and size of the lesion, we were only able to complete partial resection. We placed an endoloop over a piece of the gastric polyp prior to resection with a hot snare (fig. 4). This maneuver was repeated several times. The polyp was reduced in size by $>50 \%$, with the longest protruding piece being $<3 \mathrm{~cm}$ in length. No immediate complications were noted and the patient tolerated the procedure well. Pathology confirmed that all resected pieces were consistent with a gastric hyperplastic polyp. No evidence of dysplasia or malignancy was seen. Upon follow-up the patient has had no symptoms recurrence for over 1 year.

\section{Discussion}

Intussusception in the adult population occurs infrequently. When found, the vast majority of cases are located in the small or large intestine. Our patient presented with gastroduodenal intussusception, which is very uncommon and accounts for $<10 \%$ of all types of intussusceptions in adults $[1,6]$.

In this report, we describe a patient who presented with gastroduodenal intussusception from a gastric hyperplastic polyp. Although gastric antral polyps have been known to commonly prolapse through the pylorus and occasionally cause intermittent outlet obstruction, it is exceedingly rare for them to cause intussusception, as seen with our patient $[10,11]$. This gastric polyp also caused radiographic and laboratory evidence of biliary obstruction in addition to the patient's biochemical pancreatitis. His lipase peak was 3,668 U/l, but CT scan did not show radiographic evidence of pancreatitis as described in other cases of gastroduodenal intussusception $[4,12,13]$. Our case is unique in that we were able to endoscopically resect a large enough portion of the polyp to treat and prevent further recurrence of his symptoms without surgical intervention.

In a study reviewing 39 cases of prolapsing gastric polyps causing gastric outlet obstruction, endoscopic polypectomy was utilized for polyps averaging $3 \mathrm{~cm}$ in size and surgical intervention for polyps averaging $6 \mathrm{~cm}$ in size. The largest polyp removed endoscopically was $8 \mathrm{~cm}$ [10]. In our patient, we were able to reduce the size of the polyp using a combination of endoscopic techniques as described earlier, despite the polyp being $12 \mathrm{~cm}$. In a study of 274 patients with gastric hyperplastic polyps $>1 \mathrm{~cm}$ in size, there was a $1.1 \%$ transformation rate to adenocarcinoma, especially if they were pedunculated [14]. Therefore, we recommend treatment of all gastric hyperplastic polyps $>1 \mathrm{~cm}$ in order to rule out other gastric pathology [9]. If endoscopic management is not feasible, then management of gastric hyperplastic polyps and other lesions that cause intussusception includes surgical intervention by a variety of laparoscopic or open techniques $[4,5]$. 
Chahla et al.: Gastroduodenal Intussusception, Intermittent Biliary Obstruction and Biochemical Pancreatitis due to a Gastric Hyperplastic Polyp

In conclusion, we present a case of intermittent gastroduodenal intussusception, biochemical pancreatitis and biliary obstruction due to a hyperplastic gastric polyp that was managed endoscopically, with complete resolution of symptoms.

\section{Author Contributions}

E. Chahla performed the literature review, assisted in the initial manuscript, performed revisions and is the article guarantor. M.A. Kim, B.T. Beal and M.T. Ogawa performed the literature review and assisted in the initial manuscript. S. Alkaade and L. Omran performed editing of the manuscript. R.W. Garrett performed radiologic image labeling with reference in the figure legend narrative. J.R. Taylor performed the endoscopic procedures and edited the manuscript.

\section{Disclosure Statement}

The authors have no financial or other conflicts of interest to report.

\section{References}

1 Stubenbord WT, Thorbjarnarson B: Intussusception in adults. Ann Surg 1970;172:306-310.

$\longrightarrow 2$ Vinces FY, Ciacci J, Sperling DC, Epstein S: Gastroduodenal intussusception secondary to a gastric lipoma. Can J Gastroenterol 2005;19:107-108.

-3 Asai S, Kijima H, Yamamoto S, Shiraishi S, Suzuki T, Maeda Y, Matsushita H, Miyachi H: Gastroduodenal intussusception secondary to pedunculated gastric carcinoma. J Ultrasound Med 2008;27:673-676.

4 Kim DJ, Lee JH, Kim W: Gastroduodenal intussusception resulting from large hyperplastic polyp. J Gastric Cancer 2012;12:201-204.

5 Rittenhouse DW, Lim PW, Shirley LA, Chojnacki KA: Gastroduodenal intussusception of a gastrointestinal stromal tumor (GIST): case report and review of the literature. Surg Laparosc Endosc Percutan Tech 2013;23:e70-e73.

-6 Shum JS, Lo SS, Ka SY, Yeung CW, Ho JT: Gastroduodenal intussusception. Abdom Imaging 2007;32: 698-700.

7 Carmack SW, Genta RM, Graham DY, Lauwers GY: Management of gastric polyps: a pathology-based guide for gastroenterologists. Nat Rev Gastroenterol Hepatol 2009;6:331-341.

-8 Park do Y, Lauwers GY: Gastric polyps: classification and management. Arch Pathol Lab Med 2008;132: 633-640.

9 Jain R, Chetty R: Gastric hyperplastic polyps: a review. Dig Dis Sci 2009;54:1839-1846.

10 Parikh M, Kelley B, Rendon G, Abraham B: Intermittent gastric outlet obstruction caused by a prolapsing antral gastric polyp. World J Gastrointest Oncol 2010;2:242-246.

11 Meyers MA: Gastroduodenal intussusception. Am J Med Sci 1967;254:347-356.

-12 Griffin M, Carey WD, Hermann R, Buonocore E: Recurrent acute pancreatitis and intussusception complicating an intraluminal duodenal diverticulum. Gastroenterology 1981;81:345-348.

13 White PG, Adams H, Sue-Ling HM, Webster DJ: Case report: gastroduodenal intussusception - an unusual cause of pancreatitis. Clin Radiol 1991;44:357-358.

14 Kang HM, Oh TH, Seo JY, Joen TJ, Seo DD, Shin WC, Choi WC, Kim JY: Clinical factors predicting for neoplastic transformation of gastric hyperplastic polyps. Korean J Gastroenterol 2011;58:184-189. 
Chahla et al.: Gastroduodenal Intussusception, Intermittent Biliary Obstruction and Biochemical Pancreatitis due to a Gastric Hyperplastic Polyp

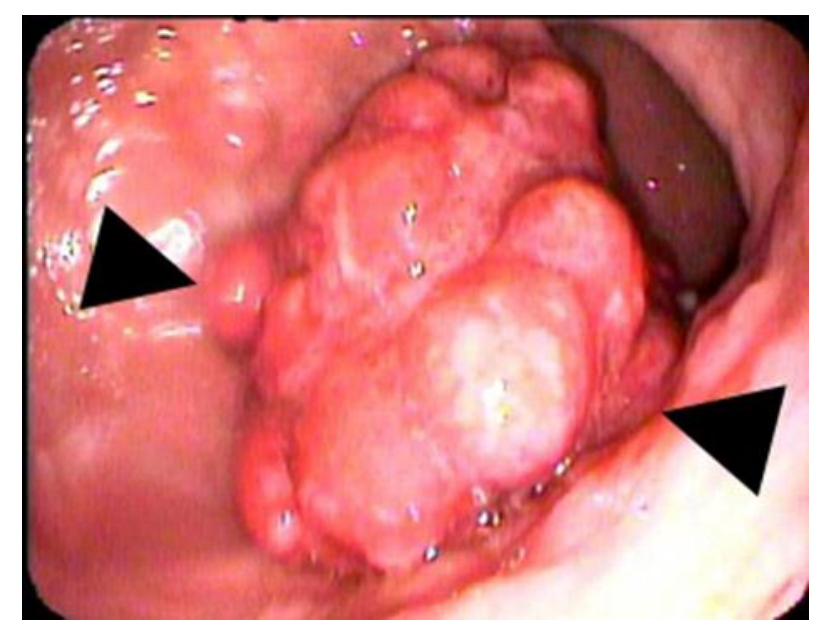

Fig. 1. Endoscopic view of the gastric polyp in the gastric antrum (between the two arrowheads).

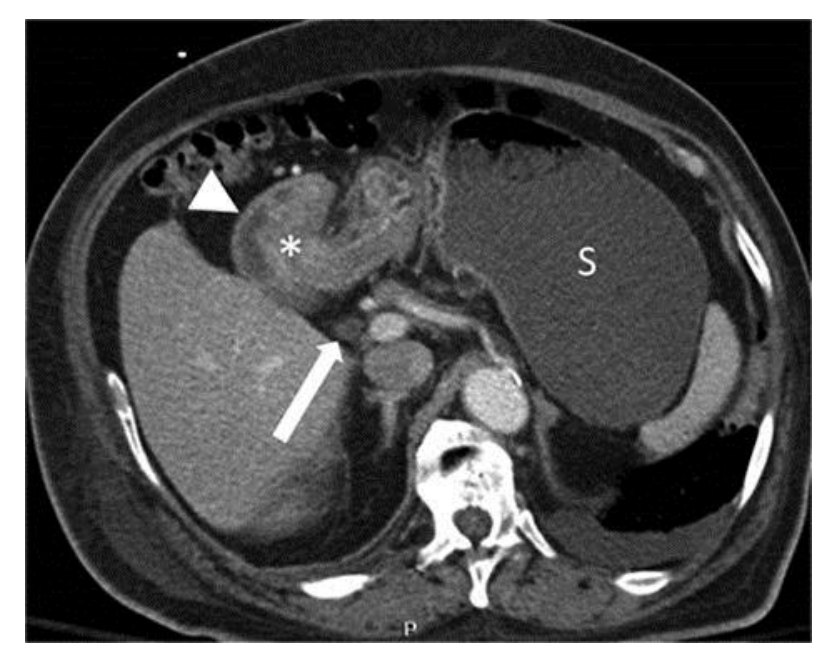

Fig. 2. Axial CT of the abdomen demonstrating the gastroduodenal intussusception (asterisk) filling the duodenal bulb (arrowhead). Note the resultant gastric distension (S) and common bile duct dilation $(1.1 \mathrm{~cm}$, arrow). 


\begin{tabular}{ll|l} 
Case Reports in & \multicolumn{2}{l}{} \\
\cline { 2 - 3 } Gastroenterology & Case Rep Gastroenterol 2014;8:371-376 & $\begin{array}{l}\text { C 2014 S. Karger AG, Basel } \\
\text { www.karger.com/crg }\end{array}$ \\
\cline { 2 - 3 } & DOI: 10.1159/000369548 &
\end{tabular}

Chahla et al.: Gastroduodenal Intussusception, Intermittent Biliary Obstruction and Biochemical Pancreatitis due to a Gastric Hyperplastic Polyp

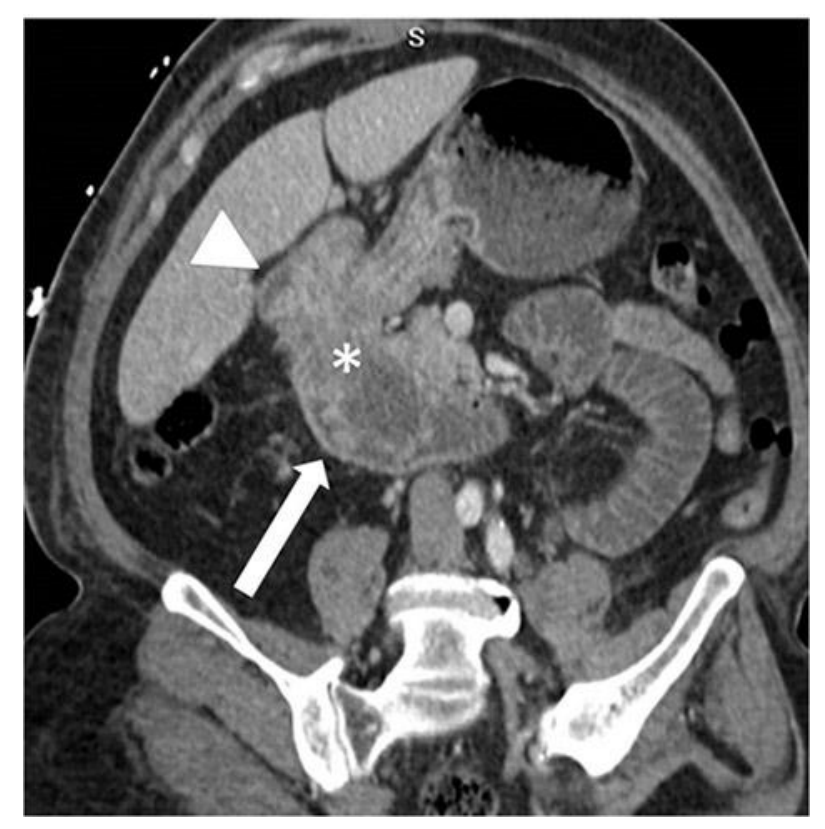

Fig. 3. Oblique coronal CT of the abdomen demonstrating the gastroduodenal intussusception (asterisk) extending beyond the duodenal bulb (arrowhead) to the junction of the 2 nd and 3rd portion of the duodenum (arrow).

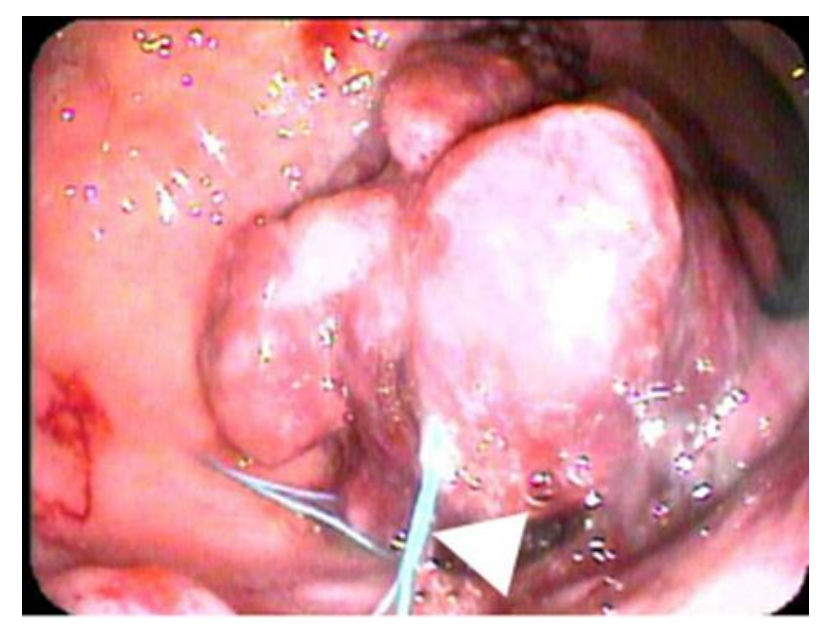

Fig. 4. Endoloop around one section of the multi-lobulated gastric hyperplastic polyp (arrowhead) prior to resection. 